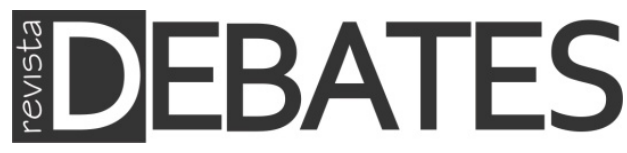

\title{
Histórico do sistema normativo de saúde no Brasil: uma análise da construção do ordenamento jurídico da saúde pós-1988
}

\author{
Historic of the health normative system in Brazil: an analysis of the \\ construction of health legal system after 1988
}

\section{Edith Maria Barbosa Ramos \\ Edson Barbosa de Miranda Netto}

\section{Resumo}

O presente artigo objetiva analisar a construção do ordenamento jurídico da saúde presente na Constituição Federal brasileira de 1988, bem como as alteraçóes constitucionais ocorridas após sua promulgação. Para tanto, será traçado um histórico do sistema normativo de saúde no Brasil desde a sua independência em 1822 até a redemocratização pós-ditadura militar e as emendas constitucionais sofridas pela Constituição Cidadã. Com relação à metodologia empregada, o presente artigo adotou a revisão sistemática. Concluiu-se que, apesar dos inegáveis avanços na garantia do direito à saúde no Brasil, o financiamento do Sistema Único de Saúde permanece sendo negligenciado, o que compromete a prestação das ações públicas de saúde.

\section{Palavras-chave}

Direito à Saúde; Brasil; Ordenamento Jurídico da Saúde; Constituição Federal; SUS.

\section{Abstract}

The present article aims to analyze the construction of the health legal system found in the brazilian Federal Constitution of 1988, as well as the constitutional changes occurred after its enactment. Therefore it will be traced a historical of the health legal system in Brazil from its Independence in 1822 to its redemocratization after the Military Dictatorship and the constitutional amendments suffered by the Citizen Constitution. The methodology adopted was the systematic review. It was concluded that, despite the undeniable advances in the right to health in Brazil, the financing of the Unified Health System remains neglected, which compromises the provision of public health actions.

\section{Keywords}

Right to Health; Brazil; Health Law; Federal Constitution; Health Unique System. 
44 | Edith Maria Barbosa Ramos e Edson Barbosa de Miranda Netto

\section{Introdução}

$\mathrm{Na}$ vigência da Constituição Cidadã, pode-se encontrar uma configuração do direito à saúde que o eleva ao patamar de direito fundamental social, devendo ser assegurado a todos, independentemente de contrapartida financeira, por meio de açóes e serviços públicos de responsabilidade do Estado. A Lei no 8.080 de 1990, no mesmo sentido, em seu art. $3^{\circ}$, parágrafo único, ao regulamentar a prestação das ações e dos serviços de saúde previstos na Constituição Federal brasileira de 1988, estabelece que também dizem respeito à garantia da saúde aquelas açôes que se destinam a assegurar às pessoas e à coletividade condiçóes de bem-estar físico, mental e social.

Indo além, autores elevam o direito à saúde ao patamar de atributo essencial da cidadania (ASENSI, 2013; POLIGNANO, 2001). Quanto a isso, Silva (2016) aduz que a cidadania, em sua concepçáo moderna, apresenta-se como condição ligada ao regime político democrático, ou seja, um atributo que qualifica as pessoas integradas na sociedade e que participam efetivamente da vida política do país. E, partindo-se da visão supramencionada, sem o adequado cuidado com a saúde da população, restaria comprometido o exercício pleno dos direitos políticos e, por consequência, o dos demais direitos consagrados na Constituição.

Entretanto, verifica-se que tal concepção ampla do direito à saúde é algo recente na história brasileira, não existindo na vigência dos ordenamentos constitucionais brasileiros anteriores. Partindo de uma compreensão do direito à saúde como mera benesse estatal vigente na fase imperial e passando pelo modelo de seguro social ligado ao mercado formal de trabalho adotado no início do século XX (ASENSI, 2013), o direito à saúde assegurado na atual ordem constitucional brasileira representa a busca por uma sociedade igualitária e democrática, na qual a populaçáo deve ter asseguradas as condiçóes para o exercício de seus direitos constitucionais.

Dessa forma, o presente trabalho objetiva compreender a construçáo do ordenamento jurídico sanitário brasileiro inaugurado com a Constituição Cidadã de 1988 - incluindo as alteraçóes realizadas posteriormente por meio da Emenda Constitucional de Revisão no 1 e das Emendas Constitucionais (EC) $n^{\circ} 27,29,42$, 51, 56, 63, 68 e 93 - a partir de uma análise dos sistemas normativos de saúde presentes ao longo da história brasileira. Isso se justifica porque, como lembram Escorel e Teixeira (2012), conhecer o processo histórico de formação do atual sistema sanitário brasileiro pode fornecer elementos importantes para a compreensão das bases, da dinâmica e dos problemas do Sistema Único de Saúde (SUS) implementado 
no Brasil.

Como referenciais teóricos a dar suporte ao presente trabalho, foram utilizadas as ideias acerca da história das políticas de saúde no Brasil presentes em Escorel e Teixeira (2012), Escorel (2012), Noronha, Lima e Machado (2012), Asensi (2013) e Lobato e Giovanella (2012), de modo se compreender as três grandes fases que compóe esse histórico, as concepções de saúde então existentes e os modelos de proteção social predominantes em cada um deles, culminando na criação do atual SUS e nas diversas alteraçóes constitucionais ocorridas desde 1988 e que, de alguma maneira, impactaram na temática do direito sanitário e de seu financiamento.

Com relação aos aspectos metodológicos, o presente artigo consiste em uma revisão sistemática, enquanto espécie de revisão de literatura, sendo analisados estudos e pesquisas anteriores acerca da história das políticas de saúde no Brasil e dos sistemas sanitários elaborados ao longo dos distintos ordenamentos jurídicos brasileiros, com o objetivo de permitir uma melhor compreensão em torno do atual quadro do direito sanitário, do SUS e das ações e serviços voltados à saúde da população.

Para tanto, está estruturado da seguinte maneira: a) análise do sistema normativo de saúde do período imperial até o desenvolvimentismo populista (1822 a 1963); b) abordagem das políticas de saúde existentes na ditadura militar brasileira até as contribuiçóes da Reforma Sanitária para a redemocratização do país (1964 a 1990); c) análise da Constituição de 1988 e o SUS nela prevista; d) exame das alterações constitucionais pós-1988 no SUS e seus impactos na garantia das ações e serviços de saúde; e) por fim, as consideraçóes finais sobre os resultados encontrados ao longo do trabalho.

\section{Do Império ao desenvolvimentismo populista pré-ditadura militar (1822 a 1963)}

Durante os períodos Colonial e Imperial, a população brasileira e seus problemas de saúde, em sua maioria, não recebiam o enfoque necessário da Medicina formal e dos profissionais formados nas Ciências Médicas. Apenas um grupo reduzido de médicos, cirurgióes e boticários, de formação europeia, atendiam somente às camadas altas da sociedade e se encontravam apenas nos grandes centros urbanos. As camadas mais pobres da população, sobretudo os escravos, dependiam da solidariedade comunal, de curandeiros e dos cuidados oferecidos por grupos religiosos (ESCOREL e TEIXEIRA, 2012).

Dessa forma, Asensi (2013) aponta que, principalmente no Império e na 
República Velha, a saúde era apresentada como uma autêntica benesse por parte do Estado, estando envolta por relaçóes de poder de natureza patrimonialista que a caracterizavam como um mero favor do Poder Público à população. Tal afirmação pode ser constatada a partir da observação da perspectiva de submissão do indivíduo à autoridade estatal através das políticas de higienização. Citadas políticas não eram elaboradas por meio de qualquer aspecto democrático, sendo impostas até mesmo mudanças arquitetônicas na estrutura urbana por influência dessas medidas - por exemplo, a Reforma Passos ocorrida na cidade do Rio de Janeiro entre 1902 e 1906.

A criação das primeiras instâncias de saúde pública no Brasil (Fisicatura-mor e Provedoria-mor de Saúde) somente em 1808, no Rio de Janeiro, com a chegada da família real, demonstra a completa falta de um sistema de políticas de saúde voltado a combater as enfermidades que assolavam a população. Tal degradação do quadro sanitário brasileiro levou o governo imperial a instituir um modelo centralizado para as atividades de saúde, com o poder central atuando na normatizaçáo dos serviços, e cabendo aos poderes locais a responsabilidade tanto de alocar recursos quanto executar as açôes de saúde (ESCOREL e TEIXEIRA, 2012).

Como exemplos desse sistema sanitário que o governo central tentou implementar, podem ser citados o estabelecimento do Instituto Vacínico do Império, da Junta Central de Higiene Pública - responsável pelas atividades de polícia sanitária -, da Inspetoria de Saúde dos Portos - responsável pela fiscalização sanitária dos portos marítimos e fluviais brasileiros e da Sociedade de Medicina do Rio de Janeiro - responsável por reunir médicos para debater sobre assuntos específicos de doenças humana, saúde e seu papel diante das questôes de saúde pública -, que ainda existe e, atualmente, recebe o nome de Academia Nacional de Medicina (ESCOREL e TEIXEIRA, 2012).

Em suma, todo o frágil sistema sanitário montado pelo governo central durante o período do Império não tinha quaisquer preocupações em melhorar o nível de saúde da população em geral. Bertolozzi e Greco (1996) lembram que os únicos objetivos eram proteger os nobres portugueses de doenças, bem como evitar grandes perdas financeiras passíveis de ocorrer em razão do excessivo número de enfermidades e epidemias existentes.

Após a Proclamação da República em 1889, alguns fatos levaram à ocorrência de epidemias de febre amarela, de peste bubônica, dentre outras (BERTOLOZZI e GRECO, 1996) intensas correntes migratórias dirigidas ao Brasil, sobretudo da Itália, Espanha e Portugal, em busca de trabalho das lavouras de café brasileiras; e insuficientes políticas sociais e de saúde que, como demonstrado acima, remontam às 
origens do país.

Pode-se enxergar esse cenário de transição do final do século XIX para o início do século XX, onde as discussóes em torno da saúde passam a permear o debate político e a crescente organização dos trabalhadores nos movimentos sindicais, que não mais aceitavam o excludente sistema de saúde entáo vigente (BRAVO, 2008).

Já no contexto da Primeira República, a questão da saúde pública e da necessidade de sua expansão para o restante da população passa adquirir relevância nos discursos em torno da política e do poder. Surge, então, o embrião do esquema previdenciário brasileiro através da Lei Elói Chaves de 1923, que criou as Caixas de Aposentadorias e Pensóes (CAPs), financiadas pela União, empresas e empregados (BRAVO, 2008).

Pode-se perceber, a partir desse período, a formação de um modelo de proteção social do tipo seguro social, ou seja, de origem bismarckiana (LOBATO e GIOVANELLA, 2012). O sistema da saúde era financiado por meio de contribuiçôes feitas por empregados e empregadores, havendo inicialmente uma divisão por categorias funcionais de trabalhadores.

Desse modo, no início do século XX, estabelece-se esse modelo intervencionista de políticas de saúde que ficou conhecido como Sanitarismo Campanhista, caracterizado pela forte atuação do governo central no sentido garantir a expansão da agricultura cafeeira. Nesse sentido, Polignano (2001) faz as seguintes consideraçóes:

Naturalmente, a falta de um modelo sanitário para o país, deixavam as cidades brasileiras a mercê das epidemias.

No início desse século, a cidade do Rio de Janeiro apresentava um quadro sanitário caótico caracterizado pela presença de diversas doenças graves que acometiam à população, como a varíola, a malária, a febre amarela, e posteriormente a peste, o que acabou gerando sérias consequências tanto para saúde coletiva quanto para outros setores como o do comércio exterior, visto que os navios estrangeiros não mais queriam atracar no porto do Rio de Janeiro em função da situação sanitária existente na cidade. [...] Este modelo de intervenção ficou conhecido como campanhista, e foi concebido dentro de uma visão militar em que os fins justificam os meios, e no qual o uso da força e da autoridade eram considerados os instrumentos preferenciais de ação (POLIGNANO, 2001, p. 4-5). 
Apesar dos avanços mencionados acima, Escorel e Teixeira (2012) lembram que as açóes do sistema de saúde pública perpetradas até a primeira metade do século XX ainda eram voltadas unicamente para as grandes cidades, sendo meramente uma resposta aos problemas advindos do desenvolvimento urbano em algumas regióes (a exemplo de São Paulo e do Rio de Janeiro) e às imposiçóes econômicas oriundas da agricultura cafeeira e de sua expansão, o que demonstra o caráter restritivo desse sistema que ainda perduraria por algumas décadas.

Conforme tais autores, a luta pela saúde e pelo saneamento dos sertôes só se intensifica a partir da atuação do Instituto Oswaldo Cruz (IOC) e de profissionais da saúde preocupados com esse grave quadro, dando origem ao chamado movimento pelo saneamento rural. A criação do denominado Departamento Nacional de Saúde Pública (DNSP) em 1919 representa essa mudança no sistema de saúde, com o governo federal passando a dar maior amplitude aos seus serviços sanitários (SANTOS, 1998).

A partir da década de 1930, em razão do processo de industrialização e de uma redefiniçáo do papel do Estado, inicia-se um rearranjo do sistema de políticas sociais de âmbito nacional como uma das respostas às constantes reivindicaçóes dos trabalhadores, que cada vez mais se organizavam politicamente para cobrar melhorias em suas condiçôes de trabalho (BRAVO, 2008).

Ao lado dos problemas da superprodução de café - e da consequente política fiscal de desvalorização da moeda nacional para facilitar sua exportação - e da grave crise de 1929, ocorre justamente uma crise do arranjo político oligárquico da denominada República do "café com leite", culminando na chegada de Getúlio Vargas à presidência em 1930 através de um golpe. Durante seu longo governo (1930-1945), Vargas procurou impor um novo projeto de construção nacional focado na integração nacional e na valorização do trabalho e da mão de obra urbana, o que resultou no enfraquecimento do olhar que estava sendo lançado sobre os sertôes (ESCOREL e TEIXEIRA, 2012).

Os mesmos autores prosseguem e afirmam que, na Era Vargas, houve uma ampliação da oferta de serviços médicos aos trabalhadores urbanos, bem como um fortalecimento do já mencionado embrião da previdência social no país através das Caixas de Aposentadorias e Pensóes (CAPs). Para alcançar esse segundo objetivo, Getúlio Vargas iniciou um movimento de criação dos Institutos de Aposentadoria e Pensóes (IAPs), cujo objetivo seria congregar trabalhadores por categorias profissionais, e não mais por empresas, formando de maneira gradativa um sistema nacional de previdência social a ser gerido pelo Estado. 
Entretanto, como pode ser percebido, todos esses benefícios, além das diversas conquistas alcançadas com a regulamentação do trabalho urbano, restringiam-se aos trabalhadores inseridos no mercado de trabalho formal, o que deixava de fora do sistema previdenciário desempregados, subempregados e trabalhadores rurais. $\mathrm{Ou}$ seja, baseando-se nas três concepçóes de saúde encontradas ao longo da história brasileira, apontadas por Asensi (2013), restava superado o sentido social da saúde enquanto mero favor ou caridade, passando-se a um serviço que seria decorrente de um direito trabalhista ou a um serviço privado, mas que ainda estava distante do atual sentido de saúde enquanto direito.

Após o fim do Estado Novo, durante o Governo Dutra, no âmbito da saúde pública, o Sanitarismo Campanhista - surgido no início do século XX, conforme mencionado, e de índole centralizadora e autoritária - alcança o seu auge, com o governo realizando concessóes na seara social, mas buscando controlar e frear o crescimento da ideologia socialista/comunista no contexto da Guerra Fria (ESCOREL e TEIXEIRA, 2012).

Bertolozzi e Greco (1996) lembram que, com o plano SALTE (Saúde, Alimentação, Transporte e Energia), o presidente Dutra apresentava a questão da saúde pública como uma de suas prioridades de governo, mas, ainda que fosse retoricamente elevada ao posto de "questão social", a saúde nunca foi realmente opção prioritária da política de gastos do governo central.

Durante o governo de Juscelino Kubitschek (1956-1961), de coligação denominada Nacional-Desenvolvimentista, houve a abertura da economia ao capital internacional, passando a haver forte pressão por parte do empresariado no que se referia à eficiência das indústrias. $\mathrm{Na}$ área da saúde, o Congresso de Hospitais, ocorrido no período, respondeu a essas demandas estrangeiras, instituindo os chamados serviços médicos próprios das empresas. Encontrava-se aí, portanto, uma nova configuração dos serviços médicos de saúde privados, através do crescimento da medicina de grupo, que funcionou como um dos pilares para a implementação das políticas neoliberais no âmbito do setor saúde na atualidade (BERTOLOZZI e GRECO, 1996).

Por fim, os mesmos autores prosseguem e afirmam que, no período dos governos de Jânio Quadros e de João Goulart, que termina com o golpe militar de 1964, houve a maior participação do Ministério da Saúde no orçamento global da União, denotando uma preocupaçáo em ampliar os recursos à saúde pública. Também cabe destacar a realização da III Conferência Nacional de Saúde em 1963, 
com o objetivo de estabelecer orientaçóes sobre as políticas públicas de saúde. Essa Conferência definiu como ideologia da saúde a ser seguida a do desenvolvimento econômico, que se baseava na racionalidade do planejamento, na produtividade e na distribuição de riquezas.

\section{Do golpe militar à Reforma Sanitária (1964 a 1990)}

Com o golpe militar de 1964 e a deposição de João Goulart, as Forças Armadas tomam o poder em decorrência do temor que os setores mais conservadores da sociedade brasileira possuíam em relação às conexôes do Presidente deposto com a esquerda nacional e internacional. A partir daí, o Brasil passaria por duas décadas de seguidos governos ditatoriais e que cercearam diversos direitos e liberdades da população.

No presente tópico, abordou-se esse período da história brasileira em que os militares permaneceram no poder por mais de 20 anos, mas com maior ênfase no ordenamento jurídico da saúde e nas políticas sanitárias adotadas pelos governos militares. $\mathrm{O}$ reconhecimento constitucional do direito à saúde enquanto um direito social de todos e dever do Estado é algo bem recente na história brasileira, contrapondo-se à concepçáo predominante no período da ditadura militar, em que se privilegiavam não as açôes promovidas pelo setor público e o tratamento da questáo da saúde como uma questão coletiva, mas sim a atenção médica privatizante (BERTOLOZZI e GRECO, 1996).

Durante a ditadura militar, a sociedade brasileira se deparou com um modelo de proteção social por parte Poder Público que excluía a populaçáo de toda e qualquer participaçáo política na gestão do sistema sanitário. Este modelo tornava os trabalhadores meros financiadores do Instituto Nacional de Previdência Social (INPS) após a centralização da previdência social ocorrida em 1966 e o consequente alargamento do poder de controle do governo autoritário sobre a sociedade (RAMOS, MADUREIRA e SENA, 2013).

Para tanto, conforme descrito acima, houve a unificação das diferentes entidades de previdência até então existentes, resultando no chamado Instituto Nacional de Previdência Social (INPS). Posteriormente, graças à crescente complexidade desse sistema de saúde previdenciário e da necessidade de celebração de contratos com clínicas e hospitais da iniciativa privada para a efetiva prestação de serviços - gerando um consequente dever de fiscalização da estrutura burocrática daí resultante -, foi criado, a partir do INPS, o Instituto Nacional de Assistência Médica da Previdência Social (INAMPS) enquanto estrutura administrativa própria 
(POLIGNANO, 2001).

Estava-se diante da consolidação do modelo de proteção social em saúde do tipo seguro social (LOBATO e GIOVANELLA, 2012), surgido no Brasil ainda no início do século $\mathrm{XX}$, com o Governo Central unificando os diversos Institutos provedores dos serviços de previdência social e saúde antes divididos por categorias profissionais. Nesse sentido, Ramos, Madureira e Sena (2013) afirmam que:

Duas particularidades fundamentais que impuseram a unificação da Previdência Social (com a junção dos IAPs em 1966) podem ser expressas no aumento da interferência do Estado na sociedade e no afastamento dos trabalhadores da cena política. Nesta perspectiva, observa-se a exclusão popular da gestão da previdência (os trabalhadores tornaram-se meros financiadores da previdência) (RAMOS, MADUREIRA e SENA, 2013, p. 55).

Diferentemente dos atuais princípios da universalidade e da integralidade do atendimento, o Governo Militar restringia seu papel no setor da saúde pública somente a medidas de natureza preventiva e a atividades epidemiológicas e de vigilância sanitária. Somente a parcela da populaçáo que estivesse inserida no mercado formal de trabalho, vinculando, assim, a Previdência Social - de caráter contributivo - estaria amparada pelos serviços privados de saúde, que eram custeados e fiscalizados pelo INAMPS. As atividades de cunho assistencialista - e não contributivo permaneciam sendo prestadas pelas instituiçóes de caridade.

Ou seja, conforme já apontado anteriormente, nesse momento da história brasileira, estava-se diante de um sentido social da saúde como um mero serviço decorrente de um direito trabalhista ou como um serviço privado prestado por aqueles com condiçóes financeiras de bancá-lo (ASENSI, 2013). Aqueles sem condiçôes financeiras e excluídos do mercado formal de trabalho contavam apenas com a filantropia para receber algum tratamento.

Escorel (2012) ratifica as afirmaçôes feitas acima ao defender que, no regime militar autoritário-burocrático, configurou-se um sistema público de saúde marcado pela preponderância do modelo e da lógica previdenciária em face do próprio Ministério da Saúde, o que levou a uma concentraçáo dos recursos financeiros no setor da previdência social. Dourado (2010), a esse respeito, defende que: 
O reconhecimento do direito à saúde no Brasil é fato recente. [...] Até então, as atividades relacionadas à saúde eram consideradas serviços públicos prestados pelo Governo Central e se restringiam a algumas açôes preventivas (como campanhas de vacinação) e ao exercício do poder de polícia sanitária vinculado às açôes de vigilância sanitária e epidemiológica. As atividades assistenciais, que eram tradicionalmente oferecidas pelas instituições de caridade (as "santas casas de misericórdia”) e, fora destas, funcionavam como bens econômicos de iniciativa privada - submetidos às regras de mercado -, só passaram a integrar a esfera de atuação do Estado no século XX, mas, ainda assim, apenas como benefícios disponíveis aos trabalhadores integrantes do sistema previdenciário (DOURADO, 2010, p. 78-79).

Tal índole autoritária e restritiva do acesso à saúde durante a ditadura militar resultou em graves problemas estruturais na saúde pública brasileira, graças às próprias contradições internas do sistema (BERTOLOZZI e GRECO, 1996). Diante desse modelo de saúde previdenciário que se mostrava insuficiente e problemático, o Ministério da Saúde passa a atuar prioritariamente nas atividades de cunho curativo, de modo que "tornou-se muito mais um órgão burocrato-normativo do que um órgão executivo de política de saúde” (POLIGNANO, 2001, p.16).

O período da ditadura militar, portanto, representou o agravamento de sérios problemas estruturais herdados de períodos anteriores - pode-se citar, por exemplo, o alto índice de doenças infecciosas e parasitárias, bem como as elevadas taxas de morbidade e mortalidade infantil, sendo possível incluir a própria taxa de mortalidade da população em geral. O sistema de proteção social - incluindo o sanitário - foi expandido e burocratizado pela máquina estatal para alargar o poder de controle e amenizar as tensôes na sociedade, legitimando o regime de exceção perante a população, que permanecia excluída das instâncias decisórias (RAMOS, MADUREIRA e SENA, 2013).

Então, durante o período mais repressivo do autoritarismo do regime militar, começa a se formar toda uma base teórica e ideológica de um novo pensamento médico-social que, posteriormente, daria origem ao movimento da Reforma Sanitária. A partir de uma abordagem histórico-social dos problemas sanitários iniciada nos denominados departamentos de Medicina Preventiva nas faculdades de medicina, surgem as bases universitárias desse movimento social que propunha uma ampla mudança do sistema de saúde (ESCOREL, 2012).

Conforme Escorel (2012), os modelos de medicina preventiva e de medicina comunitária passaram a compor esse novo pensamento sobre a saúde. Citada autora 
denomina de movimento sanitário o movimento de profissionais da área da saúde e de pessoas relacionadas ao setor que compartilham o referencial médico-social na maneira de lidar com os problemas da saúde e que, através de certas políticas de caráter ideológico e teórico, busca transformar a saúde pública no Brasil, melhorando as condiçôes e a atenção da saúde pública da população brasileira, que são elementos cruciais ao exercício do direito da cidadania.

Apesar de ter sido iniciada nos anos 70, o termo "Reforma Sanitária" acaba sendo deixado de lado e só retorna nos anos de 1985/1986 durante a redemocratização. Para Paim (2008), pode-se analisar a Reforma Sanitária como um ciclo formado pelos seguintes elementos: ideia, proposta, projeto, movimento e processo. Ou seja, para o autor, a Reforma Sanitária representou uma reforma social nos seguintes sentidos: a) democratização da saúde, garantindo-se acesso universal e igualitário a um sistema único e com participação social; b) democratização do Estado e de seus aparelhos através do respeito ao pacto federativo e descentralizaçáo do processo decisório e do controle social; c) democratizaçáo da própria sociedade, que passa a alcançar os espaços de organização econômica e da cultura.

A contribuição e a influência do movimento sanitário e da Reforma Sanitária para o novo sistema normativo de saúde que viria a ser arquitetado na Assembleia Constituinte podem ser representados através dos resultados obtidos com os debates realizados na $8^{\text {a }}$ Conferência Nacional de Saúde (CNS), considerada um marco para a mudança ocorrida na saúde pública com a Constituição Federal de 1988, estabelecendo as seguintes diretrizes: a) busca pela equidade; b) garantia de acesso universal às açôes e serviços de saúde; c) aumento do financiamento público do setor da saúde; d) unificação e integração das açôes a partir de seu conteúdo - preventivas, curativas e de reabilitação - e de sua gestão; e) garantia de maiores poderes e participação da população na formulação, implementação e controle das açóes e serviços de saúde (BRAVO, 2008; ESCOREL, 2012).

A $8^{\text {a }}$ Conferência, frisa Bravo (2008), numa articulação bem diferente das anteriores, contou com a participaçáo de mais ou menos quatro mil e quinhentas pessoas, dentre as quais mil delegados. Essa mudança representou um marco, pois introduziu a sociedade civil no cenário de discussão em torno da saúde pública. Os debates saíram dos fóruns mais restritos (ABRASCO, CEBES, Medicina Preventiva, Saúde Pública) e assumiram outro patamar com a participação das entidades de representação da população: moradores, sindicatos, partidos políticos, associaçóes de profissionais e parlamento. 
54 | Edith Maria Barbosa Ramos e Edson Barbosa de Miranda Netto

Em suma, a questão da saúde ultrapassou as barreiras de uma mera análise setorial e técnica, abarcando a sociedade como um todo, sendo proposto não só um sistema unificado nos moldes beveridgianos, mas uma autêntica Reforma Sanitária.

\section{A Assembleia Nacional Constituinte e o direito à saúde}

$\mathrm{O}$ aspecto autoritário e antidemocrático presenciado durante o período da ditadura militar no Brasil começa, portanto, a ser superado com a redemocratização iniciada em 1985. A arquitetura constitucional do SUS funcionou como um espelho dos anseios e dos reclames da população e dos setores que até então não tinham participaçáo política nas decisóes em torno da saúde pública. Isso pode ser comprovado pela previsão da participação da comunidade enquanto uma das diretrizes a serem seguidas na prestação das açóes e dos serviços de saúde.

Durante o processo constituinte, Paim (2008) afirma que as propostas do movimento sanitário foram debatidas e discutidas nas seguintes instâncias da sociedade: Subcomissão de Saúde, Seguridade e Meio Ambiente, Comissão da Ordem Social e Comissão de Sistematização. Cabe ressaltar também que essa Subcomissão ouviu diversas entidades (CNRS, Conass, Secretários Municipais de Saúde, CUT, CGT, Contag, Abrasco, CFM, Presidente do INAMPS, Ministro da Saúde etc.) e recebeu projetos de texto constitucional de outras (ABRASCO, SBPC, CFM, Associação Paulista de Medicina, PT, PCB, CUT, Comissão Afonso Arinos etc.).

Após diversas tentativas de setores conservadores de frear os avanços propugnados na Reforma Sanitária para a nova ordem constitucional - frustradas em grande parte pelo árduo trabalho realizado por Ulysses Guimarães, Presidente da Assembleia Constituinte -, foi promulgada a nova Constituição da República Federativa do Brasil em 05 de outubro de 1988. No que se refere ao direito à saúde, o texto aprovado aproximou-se muito dos objetivos do movimento sanitário (PAIM, 2008).

A Constituição Federal de 1988, em seu Título VIII (Da Ordem Social), contém a seguinte previsão do direito à saúde que comprova o caráter democrático que passou a permear a previsão constitucional das políticas públicas de saúde: 
Art. 196. A saúde é direito de todos e dever do Estado, garantido mediante políticas sociais e econômicas que visem à redução do risco de doença e de outros agravos e ao acesso universal e igualitário às açóes e serviços para sua promoção, proteção e recuperação (BRASIL, 1988).

Polignano (2001) ressalta toda a mudança de perspectiva trazida por meio do Sistema Único de Saúde e afirma que o texto constitucional aponta claramente para uma concepção de SUS baseada na formulação de um modelo de sistema de saúde pública voltado para as necessidades da população, de maneira a resgatar $o$ compromisso do Poder Público com o bem-estar social, sobretudo no que tange à saúde coletiva. Assim, o direito à saúde é elevado ao patamar de direito essencial à própria cidadania.

A própria inserção do direito à saúde na seguridade social - ao lado da previdência e da assistência social - denota a busca do Constituinte Originário por elaborar uma ampla rede protetiva, capaz de amparar a população nas situaçóes da vida em que mais precisam do apoio estatal - doença, velhice, desemprego, necessidade financeira etc.

Percebe-se, por conseguinte, apenas pela dicção constitucional, a mudança na própria concepção de direito à saúde se comparada com o predomínio da visão curativa e da atenção privatizante no período da ditadura militar. Asensi (2013), ao discorrer sobre a temática, afirma que a saúde alcançou a categoria de direito fundamental com a Constituição Federal de 1988, sendo tal conquista fruto de intensos e exaustivos debates travados entre vários atores sociais e políticos em todo o processo de construçáo e promulgação do Texto Constitucional. Para o autor, a interação ocorrida entre pluralismo, política e governamentalidade resultaram na consolidaçáo constitucional desse direito, que passou a ser considerado atributo da cidadania e dever do Estado brasileiro.

Cabe destacar, ipsis litteris, o seguinte trecho acerca da reconstruçáo do direito à saúde no ordenamento brasileiro ocorrida graças à intensa participação popular no processo de redemocratização e de elaboração do novo Texto Constitucional: 
56 | Edith Maria Barbosa Ramos e Edson Barbosa de Miranda Netto

Não caberia mais a associação entre saúde e situação empregatícia, pois a Constituiçấo deveria promover a igualdade concreta de todos por meio da universalizaçáo dos direitos e, em particular, dos serviços de saúde. A política ensejou uma reconfiguração da relação entre Estado e sociedade, trazendo para seu interior uma discussão mais aprofundada a respeito de como efetivar direitos sociais.

Um terceiro elemento se refere à participação da sociedade civil, dos grupos sociais e políticos e dos diversos grupos de pressão. Uma vez que o processo de abertura democrática do Estado brasileiro foi possibilitado antes da própria Constituição, observa-se uma expressiva participação de uma pluralidade de atores sociais e políticos no processo de sua formulação e aprovaçáo. Portanto, em virtude da ampla presença de diversos seguimentos da sociedade civil e do Estado, uma característica marcante deste momento histórico é o pluralismo (ASENSI, 2013, p. 146).

$\mathrm{Na}$ atual ordem constitucional, diante dos traços característicos apontados, conforme exposto, vislumbra-se a adoção de uma concepção de saúde enquanto direito inerente à própria cidadania (ASENSI, 2013). Portanto, passou-se a estar diante de um modelo de proteçáo social em saúde do tipo seguridade social, ou seja, o financiamento das açôes e serviços públicos de saúde deverá ocorrer através de recursos públicos arrecadados com os tributos em geral, dando origem a um sistema nacional de saúde de origem beveridgiana que, conforme a OMS, seria a espécie de sistema sanitário mais eficiente - capaz de fazer mais com menos recursos -, mais equânime e, por conseguinte, com maior impacto nas condições de saúde da população (LOBATO e GIOVANELLA, 2012).

A passagem transcrita abaixo denota como a participaçáo popular na redemocratização e na redefinição do conceito de saúde contribuiu para sua compreensão enquanto um direito com aspectos individuais, coletivos e difusos. 


\begin{abstract}
Em suma, a afirmação constitucional do direito à saúde foi, no Brasil, uma experiência única. Absolutamente consentânea com a evolução do direito no final do século vinte, ela veio com as bases da política destinada a realizar esse direito e exigiu a participação popular para sua definição e implementação. Essa necessária participação do povo na realização do direito torna a política pública de saúde igualmente adequada aos requisitos postos pelo conceito contemporâneo de saúde, uma vez que ele implica - ao mesmo tempo - aspectos de direito individual, de direito coletivo e também difuso, que só podem ser justamente equacionados com a participaçáo direta do povo em sua definição (DALLARI, 2008/2009, p. 34).
\end{abstract}

Entretanto, apesar dos avanços obtidos após a edição da Constituição Federal de 1988 - a exemplo da edição das Leis no 8.080 e no 8.142 (BRASIL, 1990a; 1990b), responsáveis por regulamentar as condiçóes de garantia do direito à saúde, a estruturação do SUS e a participação da comunidade em sua gestão -, Paim (2008) ressalta a perda de espaço sociocomunitário enfrentada pela Reforma Sanitária, de modo a se tornar claro o descompasso entre o projeto inicialmente formulado e o processo efetivamente levado a cabo. Gerschman (2004), confirmando essa contradição surgida posteriormente à edição da nova Constituição, aduz o seguinte posicionamento:

Conforme já mencionado, o processo de legislação do setor não foi acompanhado pela efetivação da política, criando-se uma situação sui generis como a de se ter apenas conseguido contemplar na Constituição o modelo de saúde a ser aplicado no País, sem as condiçóes políticas necessárias para efetivá-lo. Desse modo, a Reforma Sanitária foi definida no plano legal sem que isso revertesse em melhor atendimento, prevenção ou condições de saúde da população (GERSCHMAN, 2004, p. 181).

Desse modo, no tópico seguinte, foram analisadas as diversas alterações ocorridas na Constituição Federal de 1988 que atingiram o financiamento e a execução das açóes e serviços do SUS, o que possibilitará uma melhor compreensão do atual cenário da saúde pública no Brasil. 


\section{Alterações constitucionais pós-1988 no sistema de saúde}

No início dos anos 90, diante da crise financeira e da necessidade de promoção de um ajuste fiscal, visando compensar as perdas fiscais oriundas do engessado sistema positivado na Constituiçáo Federal de 1988, o Governo Federal utilizou-se de vários mecanismos voltados ao financiamento do sistema da Seguridade Social.

Inicialmente, pode-se destacar a criação do chamado Fundo Social de Emergência (FSE) pela Emenda Constitucional de Revisão no 1 de 1994, posteriormente rebatizado de Fundo de Estabilização Fiscal (FEF), que permitia ao governo federal dispor livremente de $20 \%$ (vinte por cento) de todas as receitas arrecadas, o que reduziu o montante de recursos que deveriam compor o Fundo de Participaçáo dos Estados (FPE) e o dos Municípios (FPM). Porém, em razáo de suas constantes prorrogaçóes, esse mecanismo daria origem à Desvinculação de Receitas da União (DRU), o que acabou por comprometer o regime de transferências federais previsto originalmente pela Constituição Federal de 1988, bem como outras áreas, a exemplo da saúde, que deveriam vincular o total arrecadado pela Uniáo (DOURADO, 2010).

A partir desse mecanismo da DRU, o Governo Federal permaneceu com a autorização constitucional para não aplicar $20 \%$ (vinte por cento) dos recursos que deveriam ser integralmente destinados à seguridade social e à descentralização almejado com o FPE e com o FPM (PIOLA et al., 2013). Como mencionado acima, citado percentual acabou servindo para compensar as perdas fiscais ocorridas desde a promulgação da Constituição Federal de 1988, sendo destinado, por exemplo, para o pagamento de juros da dívida pública (DOURADO, 2010).

Entretanto, como consequência das constantes prorrogaçóes desse regime de desvinculações através de sucessivas ECs que o inseriam no Ato das Disposiçóes Constitucionais Transitórias (ADCT) - podem ser citadas as prorrogaçôes de 2000 a 2003, de 2003 a 2007, até dezembro de 2011 e até dezembro de 2015 por meio das ECs no 27, 42, 56 e 68 respectivamente -, comprometeu-se a prestação dos serviços públicos por parte de Estados e Municípios dependentes das transferências federais (BRASIL, 1988).

Como forma de contornar as dificuldades surgidas a partir da DRU, houve a criação da Contribuição Provisória sobre Movimentação Financeira (CPMF) em 1996. Referido tributo, criado a partir do Imposto Provisório sobre Movimentação Financeira (IPMF) de 1994, existiu até 2007 e seu produto da arrecadação deveria ser destinado ao Fundo Nacional de Saúde (FNS), de maneira a assegurar um fluxo de 
recursos capaz de manter o financiamento de açôes e serviços de saúde (BRASIL, 2016; PIOLA et al., 2013).

Entretanto, a CPMF teve sua finalidade original deturpada, uma vez que o setor econômico do Governo Federal passou a reduzir os recursos de seu orçamento voltados para a saúde na mesma proporçáo em que entravam os valores arrecadados com a contribuição provisória (POLIGNANO, 2001). Piola et al. (2013), em pesquisa do IPEA, confirma que a CPMF garantiu a estabilidade do financiamento das açóes e serviços públicos de saúde no seu período de existência de mais de uma década, mas não resultou em um aumento real significativo das receitas em decorrência da diminuiçáo e do redirecionamento de outras fontes de financiamento da saúde que deveriam constar no orçamento da Seguridade Social por força do princípio constitucional da diversidade da base de financiamento.

Dados do Senado Federal (BRASIL, 2016) mostram que o crescimento da receita gerada pela CPMF entre os anos de 1998 e 2006 foi de 216,1\%, ao passo em que o montante de recursos administrados pela Receita Federal evoluiu 78,4\% no mesmo período, convertendo-se para valores reais, mas menos da metade do que fora arrecadado foi efetivamente investido na área da saúde pública.

Posteriormente, no ano 2000, de modo a garantir o mandamento constitucional da descentralização do financiamento da saúde (art. 198, $\$ 1^{\circ}$, da CF), elevando o nível de participação de Estados e Municípios em relação à União, houve a edição da EC no 29, que definiu percentuais mínimos das receitas arrecadadas a serem aplicados pelos entes federados em açóes e serviços públicos de saúde. Pesquisa do IPEA de 2013 aponta para um relativo sucesso dessa EC no 29/2000 na tentativa de diminuir a dependência do SUS dos recursos de origem federal, tanto que, nos anos de 2000 a 2011, a participaçáo federal no financiamento caiu de $60 \%$ para $44 \%$ (PIOLA et al., 2013).

Conforme a mesma pesquisa, os recursos estaduais e municipais destinados para as açôes e serviços de saúde mais que triplicaram. Entretanto, apesar desse relativo sucesso na descentralização do financiamento, as graves disparidades econômicas persistem na Federação brasileira. Em decorrência disso, entes federados permanecem dependentes dos repasses constitucionais do Governo Central para o exercício suas funçóes constitucionais obrigatórias - dentre elas, a garantia da saúde (RAMOS, 2012).

O fenômeno da centralização fiscal em torno da União ganhou força a partir da utilização de outro dos mecanismos fiscais anteriormente citados: as contribuiçôes 
sociais. Acerca de sua natureza jurídica, as contribuiçôes sociais constituem-se em autênticos tributos, estando inseridas no rol maior das denominadas contribuiçôes especiais. Quanto à espécie tributária a que pertencem, Furtado (2013), destacando o atual posicionamento do STF através do seu Enunciado de Súmula no 659, defende se tratarem de espécie tributária autônoma, não se confundindo com os impostos.

Tais tributos, de competência federal exclusiva, deveriam servir para o financiamento da Seguridade Social, mas passaram a ser implementados apenas para aumentar a arrecadaçáo e recompor o orçamento da União, uma vez que a Constituição Federal não os insere no regime de repartição de receitas tributárias com Estados, DF e Municípios. Dourado (2010), a esse respeito, afirma que:

As contribuições sociais, cuja instituição é de competência exclusiva da União (C.F., art. 149), foram responsáveis pela maior parte do aumento da arrecadaçáo - e da carga tributária - logrado pelo governo federal durante os anos 90 e, consequentemente, tiveram importante papel na recomposição orçamentária da União - desviando-se de sua destinação original (DOURADO, 2010, p. 56).

Dentre as alteraçóes constitucionais que representaram relevantes avanços em matéria de saúde pública, vale destacar as ECs no 51 de 2006 e 63 de 2010. A primeira estabeleceu a obrigaçáo de lei federal dispor sobre o regime jurídico dos agentes comunitários de saúde e dos agentes de combate às endemias; já a segunda, a obrigação dessa lei regulamentadora dispor também sobre o piso salarial profissional nacional e as diretrizes para os Planos de Carreira, estabelecendo a obrigação da União, nos termos dessa lei, prestar assistência financeira complementar para o cumprimento do referido piso salarial (BRASIL, 1988).

Voltando à questáo da DRU, citado mecanismo fiscal foi novamente prorrogado até 2023 através da EC no 93 de 2016, sob o argumento da grave crise econômica e fiscal atualmente vivenciada e das dificuldades impostas pela Constituição Federal de 1988 e seu modelo rígido de despesas obrigatórias. A nova redação do art. 76 do ADCT passou, entáo, a estabelecer o seguinte: 
Art. 76. São desvinculados de órgão, fundo ou despesa, até 31 de dezembro de 2023, 30\% (trinta por cento) da arrecadação da União relativa às contribuições sociais, sem prejuízo do pagamento das despesas do Regime Geral da Previdência Social, às contribuiçôes de intervenção no domínio econômico e às taxas, já instituídas ou que vierem a ser criadas até a referida data (BRASIL, 1988).

Com essa nossa prorrogaçáo, novamente o financiamento das ações e serviços públicos de saúde resta prejudicado, uma vez que, conforme exposto anteriormente, a União historicamente vem se utilizando deste mecanismo - que deveria ser transitório - para reduzir os gastos em áreas como saúde e educação que deveriam receber percentuais fixos da arrecadação federal.

Quanto às relaçóes acerca do direito à saúde entre os entes federados, persiste a centralizaçáo de recursos arrecadados em torno do governo federal (RAMOS, 2012), apesar do crescimento da chamada "municipalizaçáo" das açóes e serviços públicos promovida no âmbito do SUS (LIMA et al., 2012), que acabou reduzindo o papel dos Estados-membros na condução das políticas de saúde. Somente nos anos 2000, como lembram Lima et al. (2012), a União passou a buscar também uma regionalização, sobretudo após o Pacto pela Saúde de 2006, de modo a expandir a participação estadual no SUS.

Ou seja, às graves alteraçóes constitucionais citadas anteriormente, somam-se a questão das graves desigualdades socioeconômicas de diferentes níveis (interregionais, interestaduais e intermunicipais) existentes na Federação brasileira (NORONHA, LIMA e MACHADO, 2012) e a tentativa do Governo Federal de aumentar as responsabilidades dos Estados e dos Municípios no conjunto de açóes e serviços de saúde mesmo sem alteraçóes no desigual regime arrecadatório existente. Isso tudo comprometeu ainda mais a plena garantia do direito à saúde previsto na Constituição Federal de 1988.

\section{Considerações finais}

Ao longo do histórico das políticas públicas sanitárias no Brasil, três concepçôes podem ser identificadas a partir da análise dos diferentes sistemas de saúde existentes ao longo do tempo: a) a concepção da saúde enquanto mero favor concedido pelo Estado aos indivíduos; b) a concepção de saúde enquanto serviço assegurado apenas àqueles inseridos no mercado formal de trabalho; c) por fim, a atual concepção de saúde enquanto direito fundamental social, sendo elemento da 
própria cidadania.

A primeira pode ser localizada no período da história brasileira que vai do Império até a Primeira República, quando as açôes e serviços de saúde assumiam a condição de benesses concedidas aos súditos pelo governo. Para além desses "favores", a populaçáo poderia contar apenas com a filantropia para contar com algum tipo de amparo nas situações de doença.

Somente no início do século XX começa a despontar a ideia de saúde vinculada a um regime previdenciário, de modo a ser assegurada somente a quem contribuísse ou a quem tivesse os recursos necessários para utilizar dos serviços médico-hospitalares privados. Estava-se diante do modelo de proteção em saúde do tipo seguro social, que resultava em um sistema de saúde de origem bismarckiana.

Nesse segundo momento na história dos ordenamentos sanitários no Brasil, o financiamento do sistema normativo de saúde se dava através de contribuiçóes feitas por empregados e empregadores. Esse modelo, porém, dava origem a uma série de iniquidades, uma vez que, mesmo após a criação do INAMPS, desempregados e trabalhadores do mercado informal restavam completamente desguarnecidos no que se refere às açóes e serviços de saúde, sendo necessário buscar os serviços privados - de custa elevado para a maioria da populaçáo - ou as instituiçóes filantrópicas para poder dispor dos serviços mais básicos de saúde.

Já a terceira concepção resultou de intensos debates e lutas travadas ao longo do autoritário governo militar, com o movimento sanitário e a Reforma por ele idealizada pleiteando um acesso universal e gratuito às açóes e serviços de saúde através de um sistema único. Somente dessa maneira o direito à saúde, entendido como pressuposto da própria cidadania, estaria assegurado.

Com o advento da Constituição Federal brasileira de 1988 e do Sistema Único de Saúde, restou materializada grande parte das diretrizes e das proposiçóes elencadas na $8^{\text {a }}$ Conferência Nacional de Saúde, que expressavam os objetivos pretendidos pela própria Reforma Sanitária brasileira. Passou-se a contar com um sistema caracterizado pelos seguintes traços: público; universal; com foco prioritário nas atividades de caráter preventivo; financiado por meio de recursos provenientes do orçamento da seguridade social dos entes da Federaçáo e de outras fontes; democrático, graças à participação ativa da comunidade nas decisóes; e guiado pelos princípios da descentralização e da regionalização.

Passa-se, portanto, ao modelo de proteção social em saúde do tipo seguridade social, com inspiração nos princípios de justiça social, onde a populaçáo passou a ter seus direitos sociais - em especial, o direito à saúde - garantidos pelo Estado 
enquanto uma condição necessária ao exercício de sua própria cidadania.

Entretanto, as diversas alteraçóes constitucionais promovidas na CF/1988 geraram reflexos na garantia do direito à saúde com o objetivo de reduzir os recursos orçamentários destinados às açóes e serviços públicos de saúde. Isso compromete a rede protetiva arquitetada pela Constituição Cidadá, atingindo os setores mais vulneráveis da sociedade que dependem do SUS para garantirem seu direito à saúde.

O direito à saúde, no atual sistema normativo sanitário, eleva-se ao patamar de direito fundamental social. Porém, partindo da análise das alteraçóes constitucionais promovidas após 1988 , fica nítido o tratamento secundário atribuído ao financiamento do SUS, o que compromete seu funcionamento.

Daí a importância em se compreender as bases históricas e todo o processo de construção do atual ordenamento jurídico da saúde no Brasil. Só assim será possível interpretar essas alterações ao Texto Constitucional de 1988 e entender seus possíveis efeitos na garantia do direito à saúde, de modo a serem elaboradas críticas focadas na preservação da conquista que foi o SUS para a população brasileira. 
- Edith Maria Barbosa Ramos é Pós-Doutora em Direito Sanitário pela Fundação Oswaldo Cruz - FIOCRUZ/Brasília/DF. Doutora em Políticas Públicas pela Universidade Federal do Maranhão (UFMA). Mestre em Direito pela Universidade Federal de Minas Gerais (UFMG). Graduada em Direito pela UFMA. Professora do Departamento de Direito e do Mestrado em Direito e Instituições do Sistema de Justiça da UFMA. Coordenadora do Núcleo de Estudos em Direito Sanitário (NEDISA/UFMA). Professora e Pesquisadora da Universidade CEUMA. E-mail: edithramosadv@yahoo.com.br.

Edson Barbosa de Miranda Netto é Mestre em Direito e Instituições do Sistema de Justiça pela UFMA. Especialista em Direito Constitucional pela Universidade Anhanguera Uniderp LFG. Graduado em Direito pela UFMA. Membro do Núcleo de Estudos em Direito Sanitário da UFMA (NEDISA/UFMA). E-mail: nettoedson@hotmail.com.

\section{Referências}

ASENSI, Felipe Dutra. Direito à saúde: práticas sociais reivindicatórias e sua efetivação. Curitiba: Juruá, 2013.

BERTOLOZZI, Maria Rita; GRECO, Rosangela Maria. As políticas de saúde no Brasil: reconstrução histórica e perspectivas atuais. Revista da Escola de Enfermagem da USP, São Paulo, v. 30, n. 3, p. 380-398, dez. 1996.

BRASIL. Constituiçâa da República Federativa do Brasil. 5 de outubro de 1988. Disponível em: <https://www.planalto.gov.br/ccivil_03/constituicao/constituicao.htm>. Acesso em: 02 jun. 2015.

BRASIL. Senado Federal. $\quad$ CPMF. 2016.2 Disponível em: <http://www12.senado.leg.br/noticias/entenda-o-assunto/cpmf>. Acesso em: 01 out. 2016.

BRASIL. Lei $n^{o}$ 8.080. 19 de setembro de 1990a. Disponível em: <http://www.planalto.gov.br/ccivil_03/Leis/L8080.htm >. Acesso em: 10 dez. 2015.

BRASIL. Lei $n^{o}$ 8.142. 28 de dezembro de 1990b. Disponível em: <http://www.planalto.gov.br/ccivil_03/LEIS/L8142.htm>. Acesso em: $10 \mathrm{dez} .2015$.

BRAVO, Maria Inês Souza. Política de saúde no Brasil. Cuiabá: Secretaria de Estado de Saúde de Mato Grosso, 2008. Disponível em: <http://www.saude.mt.gov.br/ces/arquivo/2163/livros>. Acesso em: 11 dez. 2015.

DALLARI, Sueli Gandolfi. A construção do direito à saúde no Brasil. Revista de Direito Sanitário, São Paulo, v. 9, n. 3, p. 9-34, nov. 2008/fev. 2009. 
DOURADO, Daniel de Araújo. Regionalização e federalismo sanitário no Brasil. 2010. $183 \mathrm{f}$. Dissertação (Mestrado em Medicina) - Faculdade de Medicina, Universidade de São Paulo, São Paulo, 2010.

ESCOREL, Sarah. Histórias das políticas de saúde no Brasil de 1964 a 1990: do golpe militar à reforma sanitária. In: GIOVANELLA, Lígia; ESCOREL, Sarah; LOBATO, Lenaura de Vasconcelos Costa; NORONHA, José Carvalho de; CARVALHO, Antonio Ivo de (Orgs.). Políticas e sistema de saúde no Brasil. Rio de Janeiro: Editora FIOCRUZ, 2012. p. 323-363.

ESCOREL, Sarah; TEIXEIRA, Luiz Antonio. Histórias das políticas de saúde no Brasil de 1822 a 1963: do império ao desenvolvimentismo populista. In: GIOVANELLA, Lígia; ESCOREL, Sarah; LOBATO, Lenaura de Vasconcelos Costa; NORONHA, José Carvalho de; CARVALHO, Antonio Ivo de (Orgs.). Políticas e sistema de saúde no Brasil. Rio de Janeiro: Editora FIOCRUZ, 2012. p. 279-321.

FURTADO, José de Ribamar. Direito financeiro. Belo Horizonte: Fórum, 2013.

GERSCHMAN, Silvia. A democracia inconclusa: um estudo da Reforma Sanitária brasileira. Rio de Janeiro: FIOCRUZ, 2004.

LIMA, Luciana Dias de; VIANA, Ana Luiza d'Ávila; MACHADO, Cristiani Vieira; ALBUQUERQUE, Mariana Vercesi de; OLIVEIRA, Roberta Gondim de; IOZZI, Fabíola Lana; SCATENA, João Henrique Gurtler; MELLO, Guilherme Arantes; PEREIRA, Adelyne Maria Mendes; COELHO, Ana Paula Santana. Regionalização da saúde no Brasil. In: GIOVANELLA, Lígia; ESCOREL, Sarah; LOBATO, Lenaura de Vasconcelos Costa; NORONHA, José Carvalho de; CARVAlHO, Antonio Ivo de (Orgs.). Políticas e sistema de saúde no Brasil. Rio de Janeiro: Editora FIOCRUZ, 2012. p. 823-852.

LOBATO, Lenaura de Vasconcelos Costa; GIOVANELLA, Lígia. Sistemas de saúde: origens, componentes e dinâmica. In: GIOVANELLA, Lígia; ESCOREL, Sarah; LOBATO, Lenaura de Vasconcelos Costa; NORONHA, José Carvalho de; CARVALHO, Antonio Ivo de (Orgs.). Políticas e sistema de saúde no Brasil. Rio de Janeiro: Editora FIOCRUZ, 2012. p. 89-120.

NORONHA, José Carvalho de; LIMA, Luciana Dias de; MACHADO, Cristiani Vieira. O Sistema Único de Saúde - SUS. In: GIOVANELLA, Lígia; ESCOREL, Sarah; LOBATO, Lenaura de Vasconcelos Costa; NORONHA, José Carvalho de; CARVALHO, Antonio Ivo de (Orgs.). Políticas e sistema de saúde no Brasil. Rio de Janeiro: Editora FIOCRUZ, 2012. p. 365-393.

PAIM, Jairnilson Silva. Reforma sanitária brasileira: contribuição para a compreensão e crítica. Salvador: EDUFBA; Rio de Janeiro: FIOCRUZ, 2008.

PIOLA, Sérgio F.; PAIVA, Andrea Barreto de; SÁ, Edvaldo Batista de; SERVO, Luciana Mendes Santos. Financiamento público da saúde: uma história à procura de rumo. Rio de Janeiro: IPEA, 2013.

POLIGNANO, Marcos Vinícius. História das políticas de saúde no Brasil: uma pequena revisão. Cuiabá: Secretaria de Estado de Saúde de Mato Grosso, 2001. Disponível em: <http://www.saude.mt.gov.br/upload/documento/16/historia-das-politicas-de-saude-no-brasil\%5B16-030112-SES-MT\%5D.pdf>. Acesso em: 10 dez. 2015.

RAMOS, Edith Maria Barbosa; MADUREIRA, Amanda Silva; SENA, Jaqueline Prazeres de. O processo de redemocratização e o novo padrão de proteção do direito à saúde no Brasil. Cadernos Ibero-Americanos de Direito Sanitário, Brasília, v. 2, n. 2, p. 51-67, jul./dez., 2013. 
66 | Edith Maria Barbosa Ramos e Edson Barbosa de Miranda Netto

RAMOS, Paulo Roberto Barbosa. Federalismo e descentralizaçấo territorial em perspectiva comparada: os sistemas do Brasil e da Espanha. Porto Alegre: Sergio Antonio Fabris Ed., 2012.

SANTOS, Luiz A. de Castro. As Origens da Reforma Sanitária e da Modernização Conservadora na Bahia durante a Primeira República. Dados, Revista Brasileira de Ciências Sociais, Rio de Janeiro, v. 41, n. 3, p. 593-633, 1998.

SILVA, José Afonso da. Curso de direito constitucional positivo. São Paulo: Malheiros, 2016.

Texto recebido em 08 de março de 2017. Aprovado em 27 de março de 2017. 